\title{
Palliative Medicine in Pakistan: A Developing Country's Perspective
}

\author{
Syed Maaz Tariq, MBBS, Mohammad Hasan, MBBS, Syed Ali Haider, MBBS \\ Department of Medicine, Jinnah Sindh Medical University, Karachi, Sindh, Pakistan
}

\section{TO THE EDITOR}

We read the paper "Oncology and Palliative Medicine: Providing Comprehensive Care for Patients with Cancer" by Finn et al with great interest. The authors are right in their assessment that palliative medicine encompasses patient care from diagnosis through potential survivorship. ${ }^{1}$ We would like to carry forward the discussion by providing a perspective on a developing nation where economic crisis and lack of awareness have taken their toll on healthcare, especially palliative medicine.

In Pakistan, palliative medicine is not recognized as a discipline, so centers have not been established and physicians are not trained in palliative care. According to the survey published by the International Observatory on End of Life Care, Pakistan has the "least favorable ratio" for palliative care facilities, with only one service existing for a population of $157,935,000 .^{2}$ The medical curriculum taught in Pakistan has neither a dedicated course for palliative medicine nor a clinical rotation related to it. Palliative medicine fellowship programs in Pakistan are lacking as well.

The world dreads the future shortage of oncologists, but the situation could be even worse for Pakistan because of the absence of palliative medicine facilities and specialists. ${ }^{3}$ Physicians in Pakistan have expressed interest in being trained in this discipline,${ }^{4}$ leaving Pakistan in a peculiar place where despite the interest by doctors, no initiative is being taken. According to a study by Smith et al, immediately starting palliative care for patients with metastatic cancer not only causes improvement in their quality of life and a high level of satisfaction but also decreases the entire outlay of treatment with no known drawbacks. ${ }^{5}$
Studies should be undertaken to assess the feasibility of initiating a palliative medicine training program in Pakistan and of incorporating it in undergraduate medical and nursing degree programs as well. International funding and training collaborations that could play a role in establishing and creating awareness regarding palliative healthcare are the need of the hour. Creating awareness could be a lifesaving step as many misunderstand palliative care to be only endof-life treatment.

\section{REFERENCES}

1. Finn L, Green AR, Malhotra S. Oncology and palliative medicine: providing comprehensive care for patients with cancer. Ochsner J. 2017 Winter;17(4):393-397.

2. Wright M, Wood J, Lynch T, Clark D. Mapping levels of palliative care development: a global view. J Pain Symptom Manage. 2008 May;35(5):469-485. doi: 10.1016/j.jpainsymman. 2007.06.006.

3. Yang W, Williams JH, Hogan PF, et al. Projected supply of and demand for oncologists and radiation oncologists through 2025: an aging, better-insured population will result in shortage. J Oncol Pract. 2014 Jan;10(1):39-45. doi: 10.1200/ JOP.2013.001319.

4. Abbas SQ, Muhammad SR, Mubeen SM, Abbas SZ. Awareness of palliative medicine among Pakistani doctors: a survey. J Pak Med Assoc. 2004 Apr; 54(4):195-199.

5. Smith TJ, Temin S, Alesi ER, et al. American Society of Clinical Oncology provisional clinical opinion: the integration of palliative care into standard oncology care. J Clin Oncol. 2012 Mar 10;30(8):880-887. doi: 10.1200/JCO.2011.38.5161. 